\title{
Direct Medical Costs of Venous Thromboembolism and Subsequent Hospital Readmission Rates: An Administrative Claims Analysis From 30 Managed Care Organizations
}

\author{
Alex C. Spyropoulos, MD, FACP, FCCP, and Jay Lin, PhD, MBA
}

\begin{abstract}
BACKGROUND: Venous thromboembolism (VTE) is a common medical condition manifested as deep vein thrombosis (DVT) or pulmonary embolism (PE). Few data exist on the total economic burden of DVT and PE.

OBJECTIVE: To (1) quantify the economic burden of DVT and PE in direct medical costs and utilization and (2) determine the rates of hospital readmission for DVT and PE.

METHODS: Hospital claims containing DVT or PE as a primary or secondary discharge diagnosis during the period February 1998 through June 2004 were identified by retrospective analysis using the Integrated Health Care Information Services (IHCIS) National Managed Care Database. For the cost analysis, we included patients that had been enrolled in a health care plan for a minimum of 30 days prior to and 365 days following the DVT or PE hospitalization. For the readmission analysis, patients were required to have a minimum length of stay of 3 days and a preenrollment of 365 days. We quantified the cost burden to the health plan by examining annual DVT- and PE-related payments made by the health plan to providers for inpatient and outpatient care.
\end{abstract}

RESULTS: Of 5 million plus discharges in the database with dates of service between February 1, 1998, and June 30, 2004, 32,193 (0.64\%) had DVT or $\mathrm{PE}$ as a primary discharge diagnosis, and $26,159(0.52 \%)$ had DVT or PE as a secondary discharge diagnosis. After application of the inclusion and exclusion criteria, there were 5,348 patients with a primary discharge diagnosis of DVT and 4,593 patients with a secondary discharge diagnosis of DVT. For PE, 2,984 patients had a primary discharge diagnosis, and 1,119 had a secondary discharge diagnosis. The hospital readmission rates within 1 year for the combined diagnoses (DVT or PE) were $5.3 \%$ for primary and $14.3 \%$ for secondary diagnoses; $44.3 \%$ of the PE readmissions occurred within the first 30 days. Within 90 days, $50.7 \%$ of DVT readmissions and $58.6 \%$ of $\mathrm{PE}$ readmissions occurred. Regarding cost for a primary diagnosis, the average total annual provider payments made by a health plan were $\$ 10,804$ for DVT and $\$ 16,644$ for PE. For secondary diagnoses, the average total annual costs were $\$ 7,594$ for DVT and $\$ 13,018$ for PE. The mean hospital cost per readmission for a recurrent DVT $(\$ 11,862)$ was higher than the mean cost for the initial hospitalization $(\$ 9,805, P=0.006)$, but the mean cost per $P E$ readmission $(\$ 14,722)$ was similar to the mean cost for the initial hospitalization $(\$ 14,146, P=0.38)$.

CONCLUSIONS: The economic burden of DVT and PE in direct medical cost is large, due not only to the initial hospitalization event, but also to the high rate of hospital readmission (5\%-14\%), over half of which occurs within 90 days.

KEYWORDS: Cost, Deep vein thrombosis, Pulmonary embolism, Venous thromboembolism, Recurrence, Managed care, Economic burden

J Manag Care Pharm. 2007;13(6):475-86

Copyright@ 2007, Academy of Managed Care Pharmacy. All rights reserved.

\section{What is already known about this subject}

- VTE is a common medical condition of particular importance in the hospital setting. In patients with major surgery, the diagnosis and treatment of an initial VTE event poses a significant economic burden to health care in the United States.

- The diagnosis and treatment of the initial VTE event incurs costs, but the VTE recurrences and long-term complications of VTE create additional costs. It was found previously that 1 in 4 patients who experienced a VTE event during the incident hospital stay had additional VTE-related events requiring hospitalization in the 21 months of follow-up. These events incurred an average health plan cost of $\$ 14,957$ per event, or $\$ 2,101$ per patient per year.

\section{What this study adds}

- The total annual health care cost for a VTE ranged from $\$ 7,594$ to $\$ 16,644$, depending on the type of event and whether it was a primary or secondary diagnosis. The hospital readmission rates of DVT or PE within 12 months were $5.3 \%$ for primary and $14.3 \%$ for secondary diagnoses.

- The recurrent DVT event was associated with $21 \%$ greater cost compared with the initial DVT event, but there was no difference in cost for the recurrent PE event compared with the initial PE event.

- The use of health plan total medical costs, including outpatient medical and pharmacy in this study, resulted in higher total costs compared with previous studies that used hospital inpatient costs.

$\mathrm{V}$ enous thromboembolism (VTE) is a common medical condition comprising deep vein thrombosis (DVT) and pulmonary embolism (PE). VTE is of particular importance in the hospital setting since more than half the cases of VTE are accounted for by institutionalization, with 24\% of the cases attributable to hospitalization for surgery. ${ }^{1}$ In the absence of prophylaxis, the incidence of objectively confirmed, hospital-acquired DVT ranges from $10 \%$ to $40 \%$ in the medical and general surgical population to as high as $40 \%$ to $60 \%$ in patients who have undergone orthopedic surgery. ${ }^{2}$ Furthermore, 


\section{Direct Medical Costs of Venous Thromboembolism and Subsequent Hospital Readmission Rates: An Administrative Claims Analysis From 30 Managed Care Organizations}

in patients who have undergone major orthopedic surgery, the mortality rate due to VTE can be as high as $5 \%$, underscoring the very high-risk nature of this population. ${ }^{2}$ Recent estimates for the incidence of VTE in the United States suggest that VTE occurs, for the first time, in 100 tol20 of every 100,000 ( 0.1\%) of the population yearly. ${ }^{3,4}$

Few data exist on the overall economic burden of VTE; however, Botteman et al. ${ }^{5}$ constructed a model to assess costeffectiveness of DVT prophylaxis in total hip replacement (THR) in the United States. They estimated the cost of diagnosis and treatment of DVT at $\$ 4,159$ and PE at $\$ 5,567$. Other analyses have provided data on the economic burden of VTE via costeffectiveness studies of prophylaxis versus no prophylaxis. ${ }^{6-8}$ A study of administrative claim records for January 1, 1997, through March 31, 2004, found that the median annualized medical costs of patients during and after the DVT or PE event were $\$ 17,512$ and $\$ 18,901$, respectively. ${ }^{9}$

It is also important to note that the economic burden of VTE is not confined to the diagnosis and treatment of the initial event. Previous studies have demonstrated that a history of VTE is a strong independent risk factor for recurrent VTE in medical patients..$^{10,11}$ Furthermore, $7 \%$ to $14 \%$ of patients with a VTE will have a recurrent event within 1 year, ${ }^{12-15}$ a figure that rises to approximately $30 \%$ at 10 years. ${ }^{15,16}$ It has been established that, in high-risk surgical patients, the majority of recurrent VTE occurs shortly after the initial event, most frequently in the first 3 months. ${ }^{13}$ These types of readmissions, especially within 30 days of the original hospital discharge, represent a major concern of quality patient care at hospitals. Moreover, the type of recurrent VTE episode appears to be strongly correlated to the initial VTE. For example, DVT accounted for $86 \%$ of recurrent VTE after an initial DVT, and PE accounted for $66 \%$ of recurrent VTE after an initial PE. ${ }^{17}$ In addition to recurrent VTE, other long-term complications include postthrombotic syndrome $e^{18}$ and pulmonary hypertension. ${ }^{19}$

The extended cost of long-term complications of VTE has been investigated in a small number of studies. In patients who had undergone THR, the average lifetime costs associated with long-term complications of VTE was $\$ 3,069$ per patient. ${ }^{20}$ Similarly, in the study by Botteman et al..$^{5}$, the annual cost of long-term events in patients with VTE after THR was $\$ 3,798$ for DVT and $\$ 6,404$ for PE. In an analysis of administrative claims from 2 large U.S. health care plans, Bullano et al. found during a 21-month follow-up of patients who experienced a VTE event that $13.4 \%$ of patients experienced an average of 1.26 recurrent VTE events that required hospitalization, with an average cost of $\$ 5,736$ per event. ${ }^{21}$

Although data exist to show that VTE and its sequelae pose a considerable medical problem, little data exist on the absolute cost burden of VTE. The present study therefore used actual health care plan reimbursement costs compiled in a large managed care database, containing records from across the
United States, to investigate the cost burden of not only initial but also hospital readmission for DVT and PE in the general population. The costs associated with a primary diagnosis of VTE are relatively clear as being all costs included during that hospitalization. Patients with VTE as a secondary diagnosis (and therefore with comorbidities) represent an interesting group to compare costs against patients with VTE as a primary diagnosis, since not all hospital costs of these patients are associated with the VTE event. Therefore, this study also investigated the costs associated with DVT and PE in patients with VTE as a secondary diagnosis.

\section{Methods}

\section{Data Source}

This study was a retrospective observational cohort analysis utilizing data from the Integrated Health Care Information Services (IHCIS) National Managed Care Database, which contains claim information from approximately 30 managed care organizations and comprises patient records for approximately 25 million patients across the United States, from 1998 to 2005 .

\section{Study Population \\ Overall Economic Burden of DVT and PE}

For the analysis of the economic burden of DVT or PE, patients were included in the analysis if they had DVT and/or PE as the primary or secondary discharge diagnosis, and the hospitalization event occurred between February 1, 1998, and June 30, 2004. The first hospitalization for DVT or PE during the study period was defined as the index event. Patients were excluded if they did not have continuous health care plan enrollment and continuous pharmacy benefits for a minimum of 30 days prior to and 365 days following the hospitalization for DVT or PE. In addition, patients were excluded if they were aged older than 65 years and were not in the Medicare risk group (i.e., Medicare coverage with continuous pharmacy benefit from managed care organizations). Patient records that were not complete according to a prespecified list of required data fields, which included details of membership, hospitalization, outpatient medical, and outpatient pharmacy, were also excluded from the final analysis.

\section{Comparison of Hospital Reimbursement of DVT/PE Readmissions}

For the analysis of the economic burden of hospital readmission for DVT or PE, there were 2 additional criteria to ensure that these patients did have a true DVT or PE event and hospital readmission: (1) patients were required to have a minimum hospital length of stay of 3 days, and (2) patients were also required to have a minimum of 365 days where they did not have any DVT or PE hospitalization but had continuous health care plan enrollment prior to the index hospitalization (initial DVT or PE hospitalization) 


\section{Direct Medical Costs of Venous Thromboembolism and Subsequent Hospital Readmission Rates: An Administrative Claims Analysis From 30 Managed Care Organizations}

\section{Data Collection and Analysis Recurrent DVT or PE Analysis}

Demographic information was collected for all DVT and PE patients separately. To measure hospital readmission for DVT or $\mathrm{PE}$, the following data were collected for primary or secondary diagnosis of DVT or PE: type of VTE event, time to first recurrent event, and time pattern of readmission (monthly percentages of readmission from the first month to 12 months after first discharge). Only reimbursed hospitalization costs were compared for both initial VTE admission and readmission. Outpatient medical and pharmacy costs were not measured and compared between the initial VTE admission and readmission, leading to patients being treated as outpatients in the emergency room not being included in the costs. In the evaluation of VTE hospital readmission rate, it was required that the initial DVT or PE hospital admission be followed by a DVT or PE hospital readmission within the required time period. In the evaluation of the time pattern of DVT or PE hospital readmission, only more specific readmission types are measured: an initial DVT admission followed by a DVT readmission or an initial PE admission followed by a PE readmission.

\section{Total Economic Burden of DVT or PE Analysis}

To measure the economic burden of VTE, the following data were collected separately for primary or secondary diagnosis of DVT or PE: type of VTE event, length of hospital stay, and average total annual reimbursement for DVT or PE-related inpatient costs, outpatient medical costs, outpatient procedure costs and outpatient pharmacy costs. In this analysis, VTErelated inpatient and outpatient pharmacy costs were defined as those incurred through use of a VTE treatment-related drug, namely unfractionated heparin (UFH), a low-molecular-weight heparin (LMWH: ardeparin, dalteparin, enoxaparin, or tinzaparin), or danaparoid, warfarin, or fondaparinux. VTE-related outpatient procedure costs were defined as those incurred through use of a VTE diagnosis and treatment-related procedures (Appendixes A and B).

\section{Cost Calculations}

Costs associated with various measures of resource utilization were reported in the IHCIS database on the basis of actual reimbursement by the participating health care plans, and as such, only costs that were reimbursed by health care plans are included in this analysis. For inpatient professional services and outpatient services, only the cost associated with a DVT or PE diagnosis was used in the calculation. For outpatient lab procedures and prescription cost, only procedures or drugs related to the diagnosis and management of VTE were used in the cost calculation (Appendixes A and B).

Patients with DVT or PE as secondary discharge diagnoses were matched by primary diagnosis, and only the portion of hospital facility cost that was attributable to DVT or PE was estimated and used for the total annualized health care cost. The DVT or PE attributable hospital facility cost is defined as the difference of hospital facility cost between the patient cohort with secondary diagnoses of DVT or PE and a control patient cohort. For each member in the DVT or PE patient cohort, up to 3 nonDVT or non-PE members were selected from the database to form the control cohort based on the following matching criteria: same sex and geographical census region, $\leq 5$-year age difference, and the same primary hospital discharge diagnosis (based on International Classification of Diseases, Ninth Revision, Clinical Modification [ICD-9-CM] codes).

Data and costs analysis were performed using SAS 8.2 software (SAS Institute Inc., Cary, NC). The Student's $t$ test assuming unequal variances was carried out to test the statistical significance of the difference in the total hospitalization costs between DVT or PE readmission and the initial DVT or PE hospitalization. A $P$ value below 0.05 was considered as statistically significant in this study.

\section{Results}

\section{Patient Population}

A total of 14,108 patients met the inclusion criteria of this study (Figure 1). Of these patients, 5,348 had a primary diagnosis of DVT in the index hospitalization, 2,984 had a primary diagnosis of PE, a further 5,776 patients had a secondary diagnosis of DVT and/or PE in the index hospitalization (4,593 DVT, 1,119 PE alone, and 64 DVT and PE).

Patients with a primary diagnosis were younger (mean age 53.9 years for the DVT-alone group and 52.7 for the PE-alone group) compared with patients with DVT or PE as a secondary diagnosis (mean age 55.5 and 54.6 years, respectively). Patients were predominantly female and came from a number of different census regions (Table 1).

\section{Hospital Readmission Rate for DVT or PE as Primary or Secondary Diagnosis}

In patients with a DVT or PE as the primary diagnosis, the rate of hospital readmission for DVT or PE over 1 year was $5.3 \%$, while readmission was much higher in patients with DVT or $\mathrm{PE}$ as a secondary diagnosis, reaching a rate of $14.3 \%$ by 1 year (Figure 2). A clear trend of early occurrence was observed in patients with either DVT or PE as the primary diagnosis, with $27.1 \%$ of hospital readmissions for DVT and $44.3 \%$ of hospital readmissions for $\mathrm{PE}$ occurring in the first 30 days after the initial event (Figure 3A). A total of $50.7 \%$ of all hospital readmissions for DVT, and 58.6\% of all hospital readmissions for PE had occurred within 90 days of the initial event. Similar trends were observed in patients with DVT or PE as a secondary diagnosis, with $22.8 \%$ and $46.4 \%$ of all hospital readmission for DVT having occurred at 30 and 90 days respectively, and $32.8 \%$ and $51.6 \%$ of all hospital readmission for PE having occurred at the same time points (Figure 3B). 
Direct Medical Costs of Venous Thromboembolism and Subsequent Hospital Readmission Rates:

An Administrative Claims Analysis From 30 Managed Care Organizations

\section{FIGURE 1 Study Population for the Determination of Overall Economic Burden of DVT or PE}

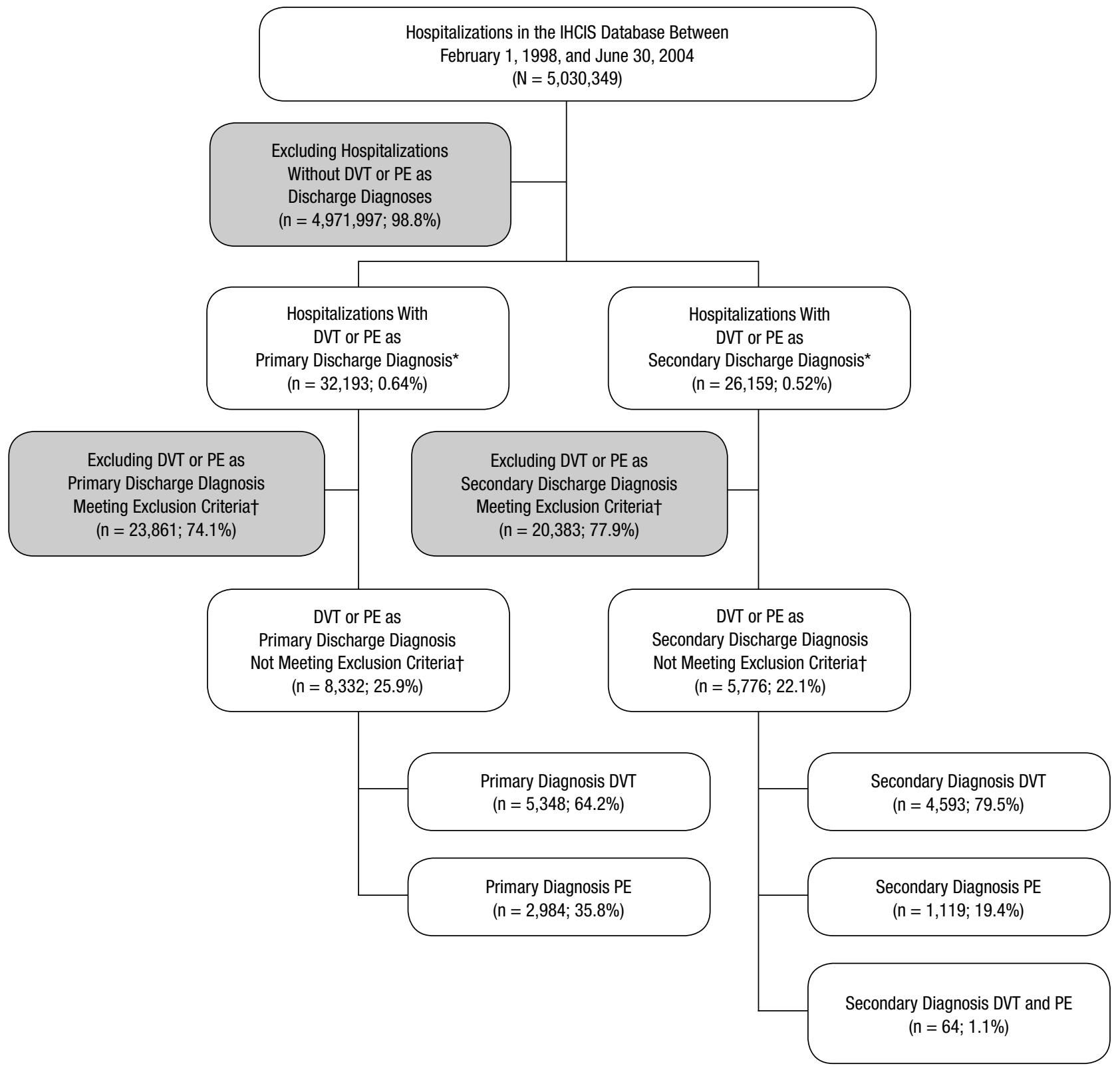

* Discharge diagnosis determined with ICD-9 codes 451.1, 451.11, 451.19, 451.2, 451.9, 453.8, 453.9, 453.4, 453.40, 453.41, 453.42, 444.21, 444.81, 451.0, or 997.2

for DVT, and 415.1, 415.11, or 415.19 for PE.

+ Exclusion criteria:

- No continuous health care plan enrollment and continuous pharmacy benefit for a minimum of 30 days prior to, and 365 days following, the DVT or PE hospitalization.

- Age $>65$ years and not in the Medicare risk group.

- Incomplete patient records.

DVT=deep vein thrombosis; ICD-9=International Classification of Diseases, Ninth Revision; PE=pulmonary embolism. 
Direct Medical Costs of Venous Thromboembolism and Subsequent Hospital Readmission Rates: An Administrative Claims Analysis From 30 Managed Care Organizations

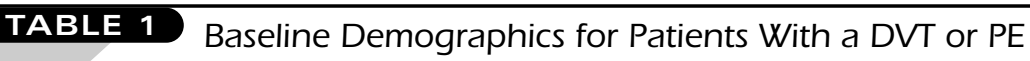

\begin{tabular}{|c|c|c|c|c|c|}
\hline & $\begin{array}{c}\text { DVT as } \\
\text { Primary Diagnosis * }\end{array}$ & $\begin{array}{c}\text { PE as } \\
\text { Primary Diagnosis * }\end{array}$ & $\begin{array}{c}\text { DVT as } \\
\text { Secondary Diagnosis }\end{array}$ & $\begin{array}{c}\text { PE as } \\
\text { Secondary Diagnosis }\end{array}$ & $\begin{array}{c}\text { DVT and PE as } \\
\text { Secondary Diagnosis }\end{array}$ \\
\hline No. of patients & 5,348 & 2,984 & 4,593 & 1,119 & 64 \\
\hline Age (mean) & 53.9 & 52.7 & 55.5 & 54.6 & 57.6 \\
\hline Female (\%) & 54 & 57 & 54 & 53 & 49 \\
\hline \multicolumn{6}{|l|}{ Census region (\%) } \\
\hline East North Central & 2.6 & 3.2 & 1.9 & 2.7 & 2.9 \\
\hline East South Central & 1.6 & 0.7 & 0.9 & 0.3 & 1.4 \\
\hline Middle Atlantic & 30.4 & 20 & 25.8 & 23.9 & 20.0 \\
\hline Mountain & 6 & 6.9 & 8.8 & 3.4 & 7.1 \\
\hline National $\dagger$ & 24.5 & 32 & 34.2 & 42.8 & 51.4 \\
\hline New England & 18.4 & 22.6 & 17.3 & 16.5 & 8.6 \\
\hline Other & 0.1 & 0.1 & 0.2 & 0.1 & 0.0 \\
\hline Pacific & 0.4 & 0.7 & 0.5 & 0.2 & 0.0 \\
\hline South Atlantic & 5 & 5.3 & 3.6 & 4.4 & 2.9 \\
\hline West North Central & 5.3 & 4.5 & 2.9 & 2.1 & 4.3 \\
\hline West South Central & 5.6 & 3.9 & 4.1 & 3.6 & 1.4 \\
\hline \multicolumn{6}{|c|}{$\begin{array}{l}\text { * Primary DVT and primary PE are mutually exclusive; either DVT or PE was the primary diagnosis. } \\
\text { † Some health care plan members are grouped into a generic "National" region to protect their identities when the combination of their medical and demographic } \\
\text { information is considered as "infrequent" and thus can be used to potentially identify the members from the combinations. } \\
\text { DVT=deep vein thrombosis; PE=pulmonary embolism. }\end{array}$} \\
\hline
\end{tabular}

\section{The Economic Burden of Hospital Readmission for DVT or PE}

In patients with hospital readmission for a DVT or PE as primary diagnosis, the costs associated with the readmission were higher than the initial hospitalization (Figure 4). For patients with a DVT, total hospitalization cost was significantly greater by $\$ 2,057$ ( $21 \%$, from $\$ 9,805$ to $\$ 11,862, P=0.006$ ), primarily due to a trend of increased length of hospital stay for the recurrent episode (from 7.7 to 8.7 days, $P=0.17$ [Appendix C]). For patients who had hospital readmission for PE, the total hospitalization cost for the readmission was $\$ 14,722$ compared with $\$ 14,146$ for the initial hospitalization $(P=0.38)$. Length of hospital stay was 7.6 and 7.4 days, respectively $(P=0.44$ [Appendix C]).

\section{Resource Use and Economic Burden of VTE as the Primary Diagnosis}

The average total annualized health care cost of a patient with a primary diagnosis of DVT or PE was $\$ 10,804$ and $\$ 16,644$, respectively (Table 2). The majority of the costs for both DVT and PE were hospitalization facility costs $(\$ 8,228$ and $\$ 13,223$ per patient, respectively), with hospitalization professional costs (\$898 and \$1,355 per patient) and outpatient procedure costs ( $\$ 821$ and $\$ 989$ per patient) being the next most costly components. Resource utilization was also higher for PE patients than for DVT patients, with a longer average length of hospital stay (7.0 vs. 5.6 days), and higher numbers of outpatient prescriptions ( 7.5 vs. 6.4 prescriptons per patient), hospitalization professional service (10.7 vs. 7.6 services per patient), outpatient procedures (19.6 vs. 15.5 procedures per patient), and outpatient office visits (3.5 vs. 3.2 visits per patient) (Table 3). For patients with a primary diagnosis of DVT or PE, the secondary comorbidity is widely distributed among a large number of conditions (see Appendex D). Patients most frequently visited internal medicine physicians (37.2\%), family physicians (20.7\%), and pulmonologists (5.9\%) for their outpatient DVT or PE care. The remaining $36.2 \%$ of patients visited a physician with other specialties or no specialty defined in the records.

\section{Breakdown of Annual Cost of DVT and PE to Health Care Plans}

The average annualized health care costs of DVT or PE were higher in the patients in the Medicare group than in the general population. In Medicare patients, the average costs for patients with a primary diagnosis of DVT or PE were $\$ 13,208$ and $\$ 20,728$ per patient, respectively, representing cost increases of $\$ 2,404$ for DVT and $\$ 4,084$ for PE over the whole population. The differences in costs were driven by increased hospital length of stay for the Medicare group. The higher costs in the 


\section{FIGURE 2 Readmission Rate for DVT or PE} as Primary or Secondary Diagnosis

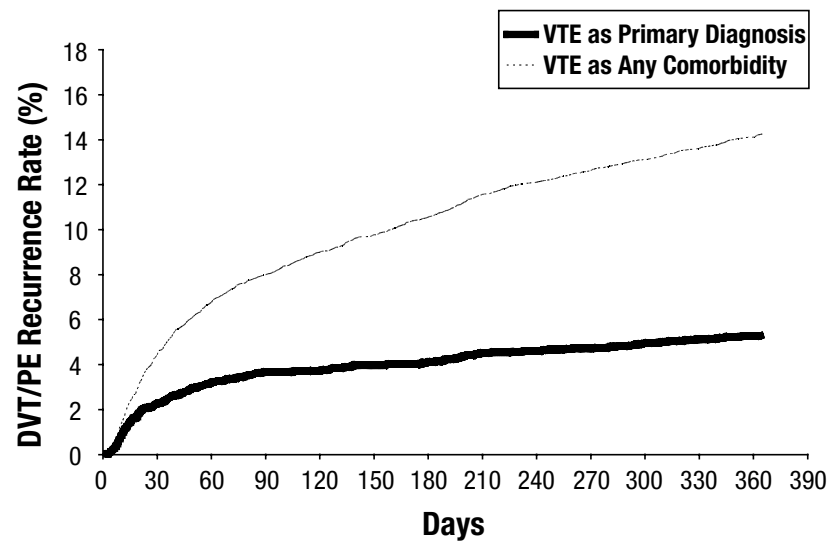

* Readmissions with hospital stay less than 3 days were excluded. $D V T=$ deep vein thrombosis; $P E=$ pulmonary embolism; VTE=venous thromboembolism.

Medicare group could be related to higher costs in patients aged $\geq 70$ years. Although average costs were similar for age groups up to 70 years, they were approximately $25 \%$ higher in patients aged $\geq 70$ years compared with the whole population (Table 4 ).

\section{Economic Burden of DVT and PE as Secondary Diagnosis}

The proportion of the average total annualized health care cost of a patient that was associated with a secondary diagnosis of DVT or PE was lower than in patients with a primary diagnosis at $\$ 7,594$ and $\$ 13,018$, respectively (Table 2 ). The cost in both the DVT and PE groups was primarily driven by hospitalization facility costs ( $\$ 5,118$ and $\$ 9,906$, respectively), followed by hospitalization professional costs, outpatient procedure costs, and outpatient prescription costs. The cost of a patient having both DVT and PE in the secondary diagnosis was extremely high at $\$ 27,909$. However, this result must be treated with caution since it was based on a low number of patients.

\section{Discussion}

In this study, utilizing actual health care plans reimbursement costs from approximately 25 million patients from across the United States. in a large managed care database to estimate the costs associated with VTE, it was found that the annualized total health care costs of admission for a primary diagnosis of DVT or PE were $\$ 10,804$ and $\$ 16,644$, respectively. Furthermore, hospital readmission for DVT or PE occurred predominantly in the first 90 days following the initial event, with a high proportion of the readmissions occurring in the first 30 days following
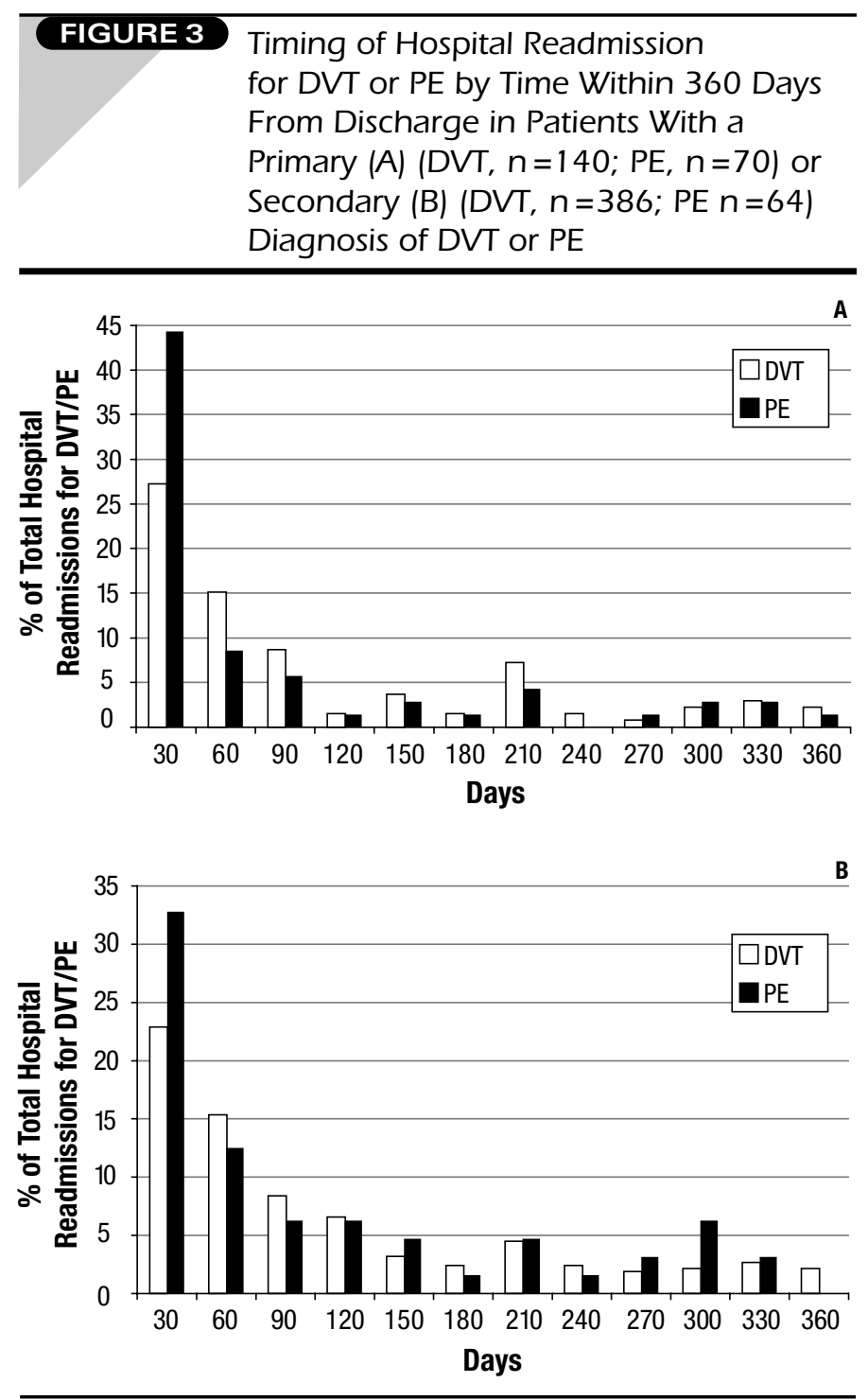

Total number of readmissions were 140 for primary DVT diagnosis, 386 for secondary DVT diagnosis, 70 for primary PE diagnosis, and 64 for secondary PE diagnosis. $D V T=$ deep vein thrombosis; $P E=$ pulmonary embolism.

the initial event. DVT or PE readmissions were associated with an average total hospitalization cost per event of $\$ 11,862$ for DVT and $\$ 14,722$ for PE. The cost of hospital readmission for DVT was $21 \%$ greater than the cost for the initial DVT event, a difference driven by a trend toward an increased length of hospital stay (an average of 7.7 days for the initial admission vs. 8.7 days for the readmission $[P=0.17])$. A similar trend was not observed for patients who had an initial PE hospitalization.

The high rate of hospital readmission for DVT or PE found in the present study within the first 30 days or first 90 days is a point of concern for the quality of VTE care in hospitals, and is 


\section{Direct Medical Costs of Venous Thromboembolism and Subsequent Hospital Readmission Rates: An Administrative Claims Analysis From 30 Managed Care Organizations}

in line with previous estimates. ${ }^{12,13,15}$ In a population-based cohort study of 1,719 patients with a first episode of DVT or PE, the cumulative percentage of patients with recurrent VTE was $5.2 \%$ at 30 days and $8.3 \%$ at 90 days. ${ }^{15}$ The cost per event of readmission for DVT and PE observed in our study was also similar to that seen in previous smaller study populations. In the cohort study of Bullano et al., ${ }^{21}$ a recurrent DVT or PE was associated with a total hospital cost of $\$ 11,419$ and $\$ 11,014$, respectively. These results highlight the importance of preventing a first episode of DVT or PE, in order to also reduce the cost burden associated with subsequent long-term complications.

The level of readmissions for VTE represents the "worst offenders" in readmission, since the patients are coming back for exactly the same disease that they just left the hospitals for, with a high proportion of readmission occurring in the first 30 days or first 90 days. This represents significant issues for the quality of care. The Joint Committion is in the process of developing a VTE prevention and care performance measurement initiative that will come out in 2008. The goal for individual hospitals will be to reduce the incidence of first episode DVT and PE as well as the incidence of hospital readmissions for DVT or PE. The use of evidence-based, guideline-mandated prophylaxis and treatments may help to improve the continuum of care and reduce the economic burden of DVT and PE in these hospitals.

The costs of DVT and PE that were observed in patients with a primary diagnosis of DVT or PE were in line with the results seen in other smaller study populations. For example, in orthopedic surgery patients, the cost difference for the mean inpatient costs compared with patients without a VTE were $\$ 7,769$ for those patients with a DVT and $\$ 9,176$ with a PE. ${ }^{22}$ In a study comparing outpatient LMWH with inpatient unfractionated heparin for patients with confirmed DVT, the average inpatient cost of treating DVT was estimated to be $\$ 4,696$ per hospitalization compared with $\$ 1,868$ for outpatient treatment. ${ }^{23}$ However, in a retrospective analysis in a health maintenance organization in New Mexico, the total average cost for patients treated for a DVT in hospital with unfractionated heparin was $\$ 11,930 .{ }^{24}$ A study from 2 managed care organizations, in the southeastern and western United States, reported the total costs for more than 2,000 patients admitted to the hospital with a DVT or PE. It showed that the average cost per DVT event was $\$ 7,712$ (median $\$ 3,131$ ) and $\$ 9,566$ (median $\$ 6,424$ ) for a PE event. ${ }^{21}$

Little data exists, however, on the total hospitalization cost of DVT or PE in large real-world studies that are representative of hospitals across the United States. The present study encompasses total annualized cost data from more than 12,000 patients with DVT or PE from across the United States, and the costs observed are higher than for many other studies. These higher costs compared with earlier studies may be a result of the data we used, including inpatient as well as outpatient payments to providers. Like
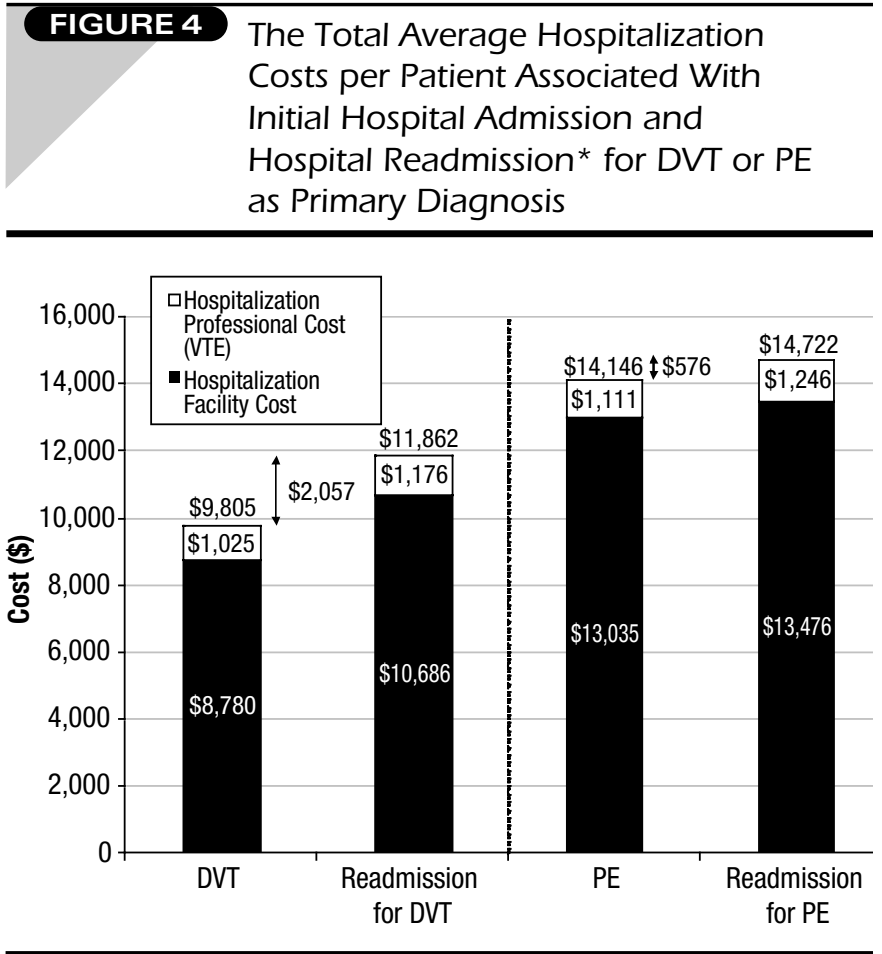

* Readmissions with hospital stay less than 3 days were excluded.

$D V T=$ deep vein thrombosis; $P E=$ pulmonary embolism; VTE=venous thromboembolism.

Bullano et al. ${ }^{21}$ we used net payer costs (i.e., after subtraction of member cost), but we used outpatient costs that included pharmacy as well as inpatient hospital costs. We also report the costs associated with a secondary diagnosis of DVT or PE, providing an estimate of the relative component that a VTE event has in the total health care cost of patients presenting with comorbidities. MacDougall et al., in a similar analysis of administrative claims data for 1997 through the first quarter of 2004, found median annualized medical costs of $\$ 17,512$ during and after the DVT event and $\$ 18,901$ during and after the PE event, representing median annualized incremental costs compared with a preevent baseline of $\$ 10,285$ for DVT patients and $\$ 12,520$ for PE patients. ${ }^{9}$ These median costs are higher than the mean costs that we found in the present study, which may be explained in part by the inclusion of recurrent VTE in the main cost calculations of the previous study reported by MacDougall and colleagues.

\section{Limitations}

Foremost among the study limitations is the difficulty in isolating the incremental medical costs associated with VTE since these patients typically have multiple comorbid conditions. For example, Bullano et al. found previously that disease severity is high in these patients, including 59\% with a history of or 


\section{Direct Medical Costs of Venous Thromboembolism and Subsequent Hospital Readmission Rates: An Administrative Claims Analysis From 30 Managed Care Organizations}

\section{TABLE 2 Economic Burden of DVT and PE as Primary and Secondary Diagnosis, Average cost per Discharge Including 12 Months of Follow-up Period}

\begin{tabular}{|c|c|c|c|c|c|c|}
\hline & Total Cost $(\$)$ & $\begin{array}{c}\text { Hospitalization } \\
\text { Facility Cost }(\$)\end{array}$ & $\begin{array}{c}\text { Hospitalization } \\
\text { Professional Cost (\$) } \\
\text { (VTE) }\end{array}$ & $\begin{array}{c}\text { Outpatient Office } \\
\text { Visit Cost (\$) } \\
\text { (VTE) }\end{array}$ & $\begin{array}{c}\text { Outpatient } \\
\text { Procedure Cost (\$) } \\
\text { (VTE) }\end{array}$ & $\begin{array}{c}\text { Outpatient } \\
\text { Prescription Cost (\$) } \\
\text { (VTE) }\end{array}$ \\
\hline $\begin{array}{l}\text { DVT as primary diagnosis } \\
(\mathrm{n}=5,348)\end{array}$ & 10,804 & $\begin{array}{c}8,228 \\
(76.2 \%)\end{array}$ & $\begin{array}{r}898 \\
(8.3 \%) \\
\end{array}$ & $\begin{array}{c}172 \\
(1.6 \%)\end{array}$ & $\begin{array}{c}821 \\
(7.6 \%)\end{array}$ & $\begin{array}{c}685 \\
(6.3 \%)\end{array}$ \\
\hline $\begin{array}{l}\text { DVT as secondary diagnosis } \\
(\mathrm{n}=4,593)\end{array}$ & 7,594 & $\begin{array}{c}5,118 \\
(67.4 \%) \\
\end{array}$ & $\begin{array}{c}959 \\
(12.6 \%) \\
\end{array}$ & $\begin{array}{c}107 \\
(1.4 \%) \\
\end{array}$ & $\begin{array}{c}783 \\
(10.3 \%) \\
\end{array}$ & $\begin{array}{c}628 \\
(8.3 \%) \\
\end{array}$ \\
\hline $\begin{array}{l}\text { PE as primary diagnosis } \\
(\mathrm{n}=2,984)\end{array}$ & 16,644 & $\begin{array}{l}13,223 \\
(79.4 \%)\end{array}$ & $\begin{array}{l}1,355 \\
(8.1 \%)\end{array}$ & $\begin{array}{c}188 \\
(1.1 \%)\end{array}$ & $\begin{array}{c}989 \\
(5.9 \%)\end{array}$ & $\begin{array}{c}889 \\
(5.3 \%)\end{array}$ \\
\hline $\begin{array}{l}\text { PE as secondary diagnosis } \\
(\mathrm{n}=1,119)\end{array}$ & 13,018 & $\begin{array}{c}9,906 \\
(76.1 \%) \\
\end{array}$ & $\begin{array}{l}1,276 \\
(9.8 \%) \\
\end{array}$ & $\begin{array}{c}130 \\
(1.0 \%) \\
\end{array}$ & $\begin{array}{c}900 \\
(6.9 \%) \\
\end{array}$ & $\begin{array}{c}805 \\
(6.2 \%) \\
\end{array}$ \\
\hline $\begin{array}{l}\text { DVT and PE as secondary } \\
\text { diagnosis }(n=64)\end{array}$ & 27,909 & $\begin{array}{l}21,097 \\
(75.6 \%)\end{array}$ & $\begin{array}{l}2,538 \\
(9.1 \%)\end{array}$ & $\begin{array}{c}176 \\
(0.6 \%)\end{array}$ & $\begin{array}{l}1,823 \\
(6.5 \%)\end{array}$ & $\begin{array}{l}2,275 \\
(8.2 \%)\end{array}$ \\
\hline
\end{tabular}

active malignancy. ${ }^{21}$ Second, the index event for patients in this study was hospitalization for either a primary or secondary diagnosis of DVT or PE, and as such, this study excludes patients who were seen in the emergency room, treated, and sent home on an LMWH or other anticoagulation. Therefore, this study would tend to overestimate the per-patient costs for VTE. On the other hand, since some patients with VTE treated in a hospital outpatient department were excluded, the incidence and prevalence of VTE would be underestimated by our methods.

Third, as with all retrospective administrative data analysis studies, there is the potential bias from missing data since some records are excluded from the analysis. However, since the sample size is large in the present study, and the missing data are not expected to be missing in a systematic manner, it is unlikely that this will have a large impact on the results. In the present study, we used a data source that did not disclose the plan names or detail information about the plans. There is, therefore, the chance that the results will not be representative of the national averages. We did however estimate the regional differences in the cost of primary DVT or PE (data not shown), and found that although differences did exist, they were not significant.

Fourth, in determining the inclusion and exclusion criteria of this study, a number of assumptions were made that may have impacted the results. We required patients to be enrolled in a health care plan before the DVT or PE event for a period of 30 days in the calculations of the total cost of DVT or $\mathrm{PE}$, and for 365 days in the calculations of the hospitalization readmission costs.

Fifth, we also required that patients who were readmitted for DVT or PE had a minimum length of stay of 3 days in both the initial and readmission hospitalization. This was a conservative approach to ensure that during both the initial hospitalizations and readmissions, a minimum length of DVT or PE treatments were administered. However, many legitimate DVT or PE patients, such as those who were admitted for only 1 to 2 days and then discharged for outpatient LMWH treatments would have been excluded due to this conservative approach, leading to an overestimation of average cost, but an underestimation of total readmissions.

There are also a number of additional complications of DVT that were not investigated in this article, but which contribute to the total cost burden of the disease, such as post thrombotic syndrome (PTS). PTS was not included due to the fact that there is not universal consensus on using ICD-9-CM code 459.1 (postphlebitic syndrome) to represent PTS. The costs reported here are therefore likely to be an underestimate of the total longterm costs associated with a first DVT.

\section{Conclusion}

This study has demonstrated the high cost burden of DVT and PE among a large national managed care population. Furthermore, it shows that readmission for DVT or PE occurs in up to $14.3 \%$ of patients, with $27.1 \%$ to $44.3 \%$ of readmissions within 30 days, and $50.7 \%$ to $57.8 \%$ occurring within 90 days. Furthermore, DVT readmissions incur a $21 \%$ greater cost than the initial episode. Hospitals have the potential to reduce the national cost burden of VTE and meet new quality initiatives by ensuring that VTE events are prevented via the use of evidencebased, guideline-mandated prophylaxis options in patients identified at risk of VTE.

\section{ACKNOWLEDGMENTS}

The authors acknowledge the valuable assistance of Essy Mozaffari, PharmD, MPH, sanofi-aventis, US, Inc., Bridgewater, New Jersey, in the design and implementation of the project and the preparation of the manuscript. 


\section{Direct Medical Costs of Venous Thromboembolism and Subsequent Hospital Readmission Rates: An Administrative Claims Analysis From 30 Managed Care Organizations}

\section{TABLE 3 Resource Utilization in 12 Months of Follow-up}

\begin{tabular}{|c|c|c|c|c|c|c|}
\hline & $\begin{array}{l}\text { Total No. of } \\
\text { Claims }\end{array}$ & Mean & SD & Median & IQR (Low) & IQR (High) \\
\hline \multicolumn{7}{|l|}{ Hospital admissions (LOS in days)* } \\
\hline DVT as primary diagnosis & 6,101 & 5.6 & 6.0 & 4.0 & 3.0 & 6.0 \\
\hline DVT as secondary diagnosis & 5,448 & 8.9 & 12.4 & 6.0 & 4.0 & 10.0 \\
\hline $\mathrm{PE}$ as primary diagnosis & 3,369 & 7.0 & 13.9 & 6.0 & 4.0 & 8.0 \\
\hline PE as secondary diagnosis & 1,357 & 10.8 & 10.3 & 8.0 & 5.0 & 14.0 \\
\hline DVT and PE as secondary diagnosis & 185 & 16.8 & 16.9 & 12.0 & 8.0 & 18.0 \\
\hline \multicolumn{7}{|l|}{ Hospital inpatient professional service* } \\
\hline DVT as primary diagnosis & 40,656 & 7.6 & 8.8 & 5.0 & 3.0 & 9.0 \\
\hline DVT as secondary diagnosis & 29,404 & 6.4 & 8.8 & 4.0 & 1.0 & 9.0 \\
\hline $\mathrm{PE}$ as primary diagnosis & 32,008 & 10.7 & 10.3 & 8.0 & 5.0 & 13.0 \\
\hline PE as secondary diagnosis & 10,123 & 9.0 & 12.7 & 5.0 & 2.0 & 12.0 \\
\hline DVT and PE as secondary diagnosis & 1,194 & 18.7 & 14.4 & 15.5 & 8.0 & 27.0 \\
\hline \multicolumn{7}{|l|}{ Physician office visits* } \\
\hline DVT as primary diagnosis & 16,921 & 3.2 & 4.5 & 2.0 & 0.0 & 4.0 \\
\hline DVT as secondary diagnosis & 10,076 & 2.2 & 4.2 & 0.0 & 0.0 & 3.0 \\
\hline $\mathrm{PE}$ as primary diagnosis & 10,418 & 3.5 & 4.8 & 2.0 & 1.0 & 4.0 \\
\hline PE as secondary diagnosis & 2,678 & 2.4 & 4.0 & 1.0 & 0.0 & 3.0 \\
\hline DVT and PE as secondary diagnosis & 203 & 3.2 & 4.6 & 2.0 & 0.0 & 4.5 \\
\hline \multicolumn{7}{|l|}{ Outpatient procedures* } \\
\hline DVT as primary diagnosis & 82,831 & 15.5 & 24.1 & 7.0 & 1.0 & 21.0 \\
\hline DVT as secondary diagnosis & 60,281 & 13.1 & 23.8 & 3.0 & 0.0 & 18.0 \\
\hline $\mathrm{PE}$ as primary diagnosis & 58,407 & 19.6 & 22.8 & 12.0 & 3.0 & 29.0 \\
\hline $\mathrm{PE}$ as secondary diagnosis & 18,536 & 16.6 & 36.0 & 7.0 & 0.0 & 21.0 \\
\hline DVT and PE as secondary diagnosis & 1,335 & 20.9 & 25.3 & 12.0 & 3.0 & 31.0 \\
\hline \multicolumn{7}{|l|}{ Outpatient prescriptions* } \\
\hline DVT as primary diagnosis & 34,033 & 6.4 & 5.4 & 6.0 & 2.0 & 10.0 \\
\hline DVT as secondary diagnosis & 23,324 & 5.1 & 5.6 & 4.0 & 0.0 & 8.0 \\
\hline $\mathrm{PE}$ as primary diagnosis & 22,502 & 7.5 & 5.2 & 7.0 & 4.0 & 11.0 \\
\hline $\mathrm{PE}$ as secondary diagnosis & 6,751 & 6.0 & 5.1 & 6.0 & 1.0 & 10.0 \\
\hline DVT and PE as secondary diagnosis & 495 & 7.7 & 6.5 & 6.0 & 4.0 & 11.0 \\
\hline
\end{tabular}

* Average use per patient, e.g., number of outpatient office visits per patient. Only resources and treatments used for treatment of a DVT or PE diagnosis are included (see Appendix B).

$D V T=$ deep vein thrombosis; $I Q R=$ interquartile range; LOS=length of hospital stay; $P E=$ pulmonary embolism

\section{DISCLOSURES}

Financial and editorial support for this research was provided by sanofi-aventis and was obtained by author Alex C. Spyropoulos, who is a paid consultant to sanofi-aventis; author Jay Lin is an employee of sanofi-aventis. Spyropoulos served as principal author of the study. Study concept and design, data collection and interpretation, and writing of the manuscript and its revision were the work of both authors.

\section{REFERENCES}

1. Heit JA, O'Fallon WM, Petterson TM, et al. Relative impact of risk factors for deep vein thrombosis and pulmonary embolism: a population-based study. Arch Intern Med. 2002;162(11):1245-48.

2. Geerts WH, Pineo GF, Heit JA, et al. Prevention of venous thromboembolism: the Seventh ACCP Conference on Antithrombotic and Thrombolytic Therapy. Chest. 2004;126(3 suppl):338S-400S. 
Direct Medical Costs of Venous Thromboembolism and Subsequent Hospital Readmission Rates:

An Administrative Claims Analysis From 30 Managed Care Organizations

\section{TABLE 4 Average Cost per Discharge for DVT or PE as Primary Diagnosis With Breakdown by Age Groups}

\begin{tabular}{c|c|c|c|c}
\hline & \multicolumn{2}{|c|}{ DVT as Primary Diagnosis } & \multicolumn{2}{c}{ PE as Primary Diagnosis } \\
\hline Age (Years) & $\mathbf{n}(\%)$ & Hospitalization Costs (\$) & $513(17.2)$ & Hospitalization Costs (\$) \\
\hline$<40$ & $919(17.2)$ & 10,291 & $734(24.6)$ & 17,415 \\
\hline $40-49$ & $1,170(21.9)$ & 10,422 & $951(31.9)$ & 14,656 \\
\hline $50-59$ & $1,611(30.1)$ & 10,219 & $491(16.5)$ & 16,417 \\
\hline $60-69$ & $911(17.0)$ & 10,747 & $295(9.9)$ & 20,883 \\
\hline$\geq 70$ & $737(13.8)$ & 13,403 & 2,984 & 16,644 \\
\hline Total/average & 5,348 & 10,804 & & \\
\hline
\end{tabular}

$D V T=$ deep vein thrombosis; $P E=$ pulmonary embolism.

3. Silverstein MD, Heit JA, Mohr DN, et al. Trends in the incidence of deep vein thrombosis and pulmonary embolism: a 25 -year population-based study. Arch Intern Med. 1998;158(6):585-93.

4. White RH. The epidemiology of venous thromboembolism. Circulation. 2003;107(23 suppl 1):14-18.

5. Botteman MF, Caprini J, Stephens JM, et al. Results of an economic model to assess the cost-effectiveness of enoxaparin, a low-molecular-weight heparin, versus warfarin for the prophylaxis of deep vein thrombosis and associated long-term complications in total hip replacement surgery in the United States. Clin Ther. 2002;24(11):1960-86.

6. Paiement GD, Wessinger SJ, Harris WH. Cost-effectiveness of prophylaxis in total hip replacement. Am J Surg. 1991;161(4):519-24.

7. Mamdani MM, Weingarten CM, Stevenson JG. Thromboembolic prophylaxis in moderate-risk patients undergoing elective abdominal surgery: decision and cost-effectiveness analyses. Pharmacotherapy. 1996;16(6):1111-27.

8. Sullivan SD, Kahn SR, Davidson BL, et al. Measuring the outcomes and pharmacoeconomic consequences of venous thromboembolism prophylaxis in major orthopedic surgery. Pharmacoeconomics. 2003;21(7):477-96.

9. MacDougall DA, Feliu AL, Boccuzzi SJ, Lin J. Economic burden of deep-vein thrombosis, pulmonary embolism, and post-thrombotic syndrome. Am J Health Syst Pharm. 2006; 63(20)(suppl):S5-S15.

10. Samama MM. An epidemiologic study of risk factors for deep vein thrombosis in medical outpatients: the SIRIUS study. Arch Intern Med. 2000;160(22):3415-20

11. Alikhan R, Cohen AT, Combe S et al. Risk factors for venous thromboembolism in hospitalized patients with acute medical illness: analysis of the MEDENOX study. Arch Intern Med. 2004;164:963-68

12. Cushman M, Tsai AW, White RH, et al. Deep vein thrombosis and pulmonary embolism in two cohorts: the longitudinal investigation of thromboembolism etiology. Am J Med. 2004;117(1):19-25

13. White RH, Zhou H, Kim J, et al. A population-based study of the effectiveness of inferior vena cava filter use among patients with venous thromboembolism. Arch Intern Med. 2000;160(13):2033-41.

14. Hansson PO, Sorbo J, Eriksson H. Recurrent venous thromboembolism after deep vein thrombosis: incidence and risk factors. Arch Intern Med. 2000;160(6):769-74

15. Heit JA, Mohr DN, Silverstein MD, et al. Predictors of recurrence after deep vein thrombosis and pulmonary embolism: a population-based cohort study. Arch Intern Med. 2000;160(6):761-68.

16. Mohr DN, Silverstein MD, Heit JA, et al. The venous stasis syndrome after deep venous thrombosis or pulmonary embolism: a population-based study. Mayo Clin Proc. 2000;75(12):1249-56
Authors

ALEX C. SPYROPOULOS, MD, FACP, FCCP, is medical director, Clinical Thrombosis Center, Lovelace Medical Center, Albuquerque, NM; JAY LIN, PhD, MBA, is senior manager, Health Economics and Outcomes Research, US Medical Affairs, sanofi-aventis, US, Inc., Bridgewater, New Jersey.

AUTHOR CORRESPONDENCE: Alex C. Spyropoulos, MD, FACP, FCCP, Medical Director, Clinical Thrombosis Center, Lovelace Medical Center, 5400 Gibson Blvd., SE, Albuquerque, NM 87108. Tel.: (505) 2627874; Fax: (505) 262-7911; E-mail: alex.spyropoulos@lovelace.com

17. Murin S, Romano PS, White RH. Comparison of outcomes after hospitalization for deep venous thrombosis or pulmonary embolism. Thromb Haemost. 2002;88(3):407-14

18. Ginsberg JS, Hirsh J, Julian J, et al. Prevention and treatment of postphlebitic syndrome: results of a 3-part study. Arch Intern Med. 2001;161 (17):2105-09.

19. Pengo V, Lensing AW, Prins MH, et al. Incidence of chronic thromboembolic pulmonary hypertension after pulmonary embolism. N Engl J Med. 2004;350(22):2257-64.

20. Caprini JA, Botteman MF, Stephens JM, et al. Economic burden of longterm complications of deep vein thrombosis after total hip replacement surgery in the United States. Value Health. 2003;6(1):59-74.

21. Bullano MF, Willey V, Hauch O, et. al. Longitudinal evaluation of health care plan cost per venous thromboembolism or bleed event in patients with a prior venous thromboembolism event during hospitalization. J Manag Care Pharm. 2005;11(8):663-73. Available at: http://www.amcp.org/data/jmcp/Origi nal\%20Research\%20663-673.pdf . Accessed June 6, 2007.

22. Ollendorf DA, Vera-Llonch M, Oster G. Cost of venous thromboembolism following major orthopedic surgery in hospitalized patients. Am J Health Syst Pharm. 2002;59(18):1750-54

23. Tillman DJ, Charland SL, Witt DM. Effectiveness and economic impact associated with a program for outpatient management of acute deep vein thrombosis in a group model health maintenance organization. Arch Intern Med. 2000;160:2926-32.

24. Spyropoulos AC, Hurley JS, Ciesla GN, de Lissovoy G. Management of acute proximal deep vein trombosis. Chest. 2002;122:108-14. 
Direct Medical Costs of Venous Thromboembolism and Subsequent Hospital Readmission Rates:

An Administrative Claims Analysis From 30 Managed Care Organizations

\section{APPENDIX A Imaging and Laboratory Procedures of Interest}

\begin{tabular}{|c|c|c|c|}
\hline Imaging Services & Description & Laboratory Services & Description \\
\hline \multirow[t]{2}{*}{$36488-36491,36493$} & \multirow{2}{*}{$\begin{array}{l}\text { Central venous catheter (placement } \\
\text { and repositioning) }\end{array}$} & 85210 & Factor II, activity* \\
\hline & & 85220 & Factor V, activity* \\
\hline $71010-71035$ & Chest radiography & 85230 & Factor VII, activity* \\
\hline $71040-71060$ & Bronchography & 85240 & Factor VIII, activity* \\
\hline 71275 & $\begin{array}{l}\text { Computed tomographic angiography, } \\
\text { chest }\end{array}$ & 85244 & Factor VIII antigenv* \\
\hline $71550-71555$ & Magnetic resonance imaging, chest & 85245 & Ristocetin cofactor* \\
\hline 75741-75746 & Pulmonary angiography* & 85246 & Von Willebrand antigen* \\
\hline $76880,76856-76857$ & Ultrasonography & 85247 & Von Willebrand factor multimers* \\
\hline $75820-75827$ & Venography, extremity, caval* & 85250 & Factor IX, activity* \\
\hline 75831-75872 & Venography, renal, adrenal, neuro & 85260 & Factor X, activity* \\
\hline 78457,78458 & Venous thrombosis imaging* & 85270 & Factor XI, activity* \\
\hline $78580-78594$ & Ventilation/perfusion lung scan & 85280 & Factor XII, activity* \\
\hline 78596 & Ventilation/perfusion study* & 85290 & Factor XIII, activity* \\
\hline \multirow[t]{2}{*}{93875} & \multirow{2}{*}{$\begin{array}{l}\text { Noninvasive study of extracranial } \\
\text { arteries (bilateral) }\end{array}$} & 85291 & Factor XIII, solubility* \\
\hline & & 85292 & Prekallikrein assay* \\
\hline \multirow[t]{2}{*}{$93880-93882$} & \multirow{2}{*}{$\begin{array}{l}\text { Duplex/unilateral scan of extracranial } \\
\text { arteries }\end{array}$} & 85293 & HMW kininogen* \\
\hline & & 85300 & Clotting inhibitors, antithrombin III, \\
\hline \multirow[t]{2}{*}{ 93886-93888 } & \multirow{2}{*}{$\begin{array}{l}\text { Transcranial Doppler study of } \\
\text { intracranial arteries (limited or } \\
\text { complete) }\end{array}$} & & activity* \\
\hline & & 85301 & Antithrombin III, antigen assay* \\
\hline \multirow[t]{3}{*}{$93922-93924$} & \multirow{3}{*}{$\begin{array}{l}\text { Noninvasive physiologic studies } \\
\text { upper/lower extremity arteries } \\
\text { including Doppler waveform analysis }\end{array}$} & 85302 & Protein $C$, antigen* \\
\hline & & 85303 & Protein C, activity* \\
\hline & & 85305 & Protein S, total* \\
\hline 93925-93931 & Duplex scan of upper/lower extremities & 85306 & Protein S, free* \\
\hline 93965 & $\begin{array}{l}\text { Doppler Continuous-wave ultrasound; } \\
\text { plethysmography* }\end{array}$ & $85378-85380$ & $\begin{array}{l}\text { Fibrin degradation products, } \\
\text { D-dimer* }\end{array}$ \\
\hline $93970-93971$ & $\begin{array}{l}\text { Compression ultrasound of extremity } \\
\text { veins* }\end{array}$ & 85420 & Plasminogen (activity)* \\
\hline \multirow[t]{2}{*}{93990} & \multirow{2}{*}{$\begin{array}{l}\text { Extremity arterial-venous studies; } \\
\text { duplex scan of hemodialysis access }\end{array}$} & 85610 & Prothrombin time $(\mathrm{PT})^{*}$ \\
\hline & & 85730 & Thromboplastin time, partial (PTT)* \\
\hline
\end{tabular}

* Events are included as outpatient disease-related resource utilization and costs.

$C P T=$ Current Procedural Terminology. 
Direct Medical Costs of Venous Thromboembolism and Subsequent Hospital Readmission Rates: An Administrative Claims Analysis From 30 Managed Care Organizations

\begin{tabular}{|c|c|}
\hline \multicolumn{2}{|c|}{$\begin{array}{ll}\text { APPENDIX B } & \text { ICD-9 Codes Used for } \\
& \text { DVT or PE Diagnosis }\end{array}$} \\
\hline \multicolumn{2}{|l|}{ DVT } \\
\hline 451.1 & Phlebitis \& thrombophlebitis deep veins lower extremity \\
\hline 451.11 & Phlebitis and thrombophlebitis of femoral vein \\
\hline 451.19 & $\begin{array}{l}\text { Phlebitis \& thrombophlebitis oth deep vessels lower } \\
\text { extremity }\end{array}$ \\
\hline 451.2 & Phlebitis \& thrombophlebitis lower extremity unspecified \\
\hline 451.9 & Phlebitis \& thrombophlebitis of unspecified site \\
\hline 453.8 & Embolism \& thrombosis of other specified veins \\
\hline 453.9 & Embolism $\&$ thrombosis of unspecified site \\
\hline 453.4 & $\begin{array}{l}\text { Venous embolism \& thrombosis deep vessels lower } \\
\text { extremity }\end{array}$ \\
\hline 453.40 & $\begin{array}{l}\text { Venous embolism \& thrombosis uns deep vessels lower } \\
\text { extremity }\end{array}$ \\
\hline 453.41 & $\begin{array}{l}\text { Venous embolism \& thrombosis deep vessels prox lower } \\
\text { extremity }\end{array}$ \\
\hline 453.42 & $\begin{array}{l}\text { Venous embolism \& thrombosis deep vessels dist lower } \\
\text { extremity }\end{array}$ \\
\hline 444.21 & Embolism \& thrombosis arteries upper extremity \\
\hline 444.81 & Embolism \& thrombosis of iliac artery \\
\hline 451.0 & Phlebitis \& thrombophlebitis sup vessels lower extremity \\
\hline 997.2 & Peripheral vascular complications nec \\
\hline \multicolumn{2}{|l|}{ PE } \\
\hline 415.1 & Pulmonary embolism \& infarction \\
\hline 415.11 & Iatrogenic pulmonary embolism \& infarction \\
\hline 415.19 & Other pulmonary embolism \& infarction \\
\hline
\end{tabular}

\begin{tabular}{|c|c|c|}
\hline APPENDIX C & \multicolumn{2}{|c|}{$\begin{array}{l}\text { Hospital Length of Stay in } \\
\text { Discharges During Initial } \\
\text { Hospitalization or Readmission* } \\
\text { for DVT or PE }\end{array}$} \\
\hline Discharge Group & Length of Stay (Days) & $P$ Value \\
\hline First DVT admission & 7.7 & \\
\hline DVT readmission & 8.7 & 0.17 \\
\hline First PE admission & 7.4 & \\
\hline PE readmission & 7.6 & 0.38 \\
\hline
\end{tabular}

* Readmissions with hospital stay less than 3 days were excluded. $D V T=$ deep vein thrombosis; $P E=$ pulmonary embolism.

\section{APPENDIX D Comorbidities in Patients With DVT and PE}

\begin{tabular}{|c|c|c|c|c|c|}
\hline $\begin{array}{l}\text { Comorbidity } \\
\text { Categories }\end{array}$ & $\begin{array}{c}1^{\circ} \\
\text { DVT } \\
(\%)\end{array}$ & $\begin{array}{c}2^{\circ} \\
\text { DVT } \\
(\%)\end{array}$ & $\begin{array}{l}1^{\circ} \\
\mathrm{PE} \\
(\%)\end{array}$ & $\begin{array}{l}2^{\circ} \\
\mathrm{PE} \\
(\%)\end{array}$ & $\begin{array}{c}2^{\circ} \\
\text { DVT + } \\
\text { PE (\%) }\end{array}$ \\
\hline $\begin{array}{l}\text { Infectious and parasitic } \\
\text { diseases }\end{array}$ & 1.6 & 1.0 & 1.5 & 1.0 & 0.7 \\
\hline Neoplasms & 6.4 & 4.1 & 5.0 & 3.4 & 4.9 \\
\hline $\begin{array}{l}\text { Endocrine, nutritional, } \\
\text { metabolic, immunity }\end{array}$ & 13.9 & 8.8 & 12.0 & 8.2 & 7.3 \\
\hline $\begin{array}{l}\text { Blood and blood- } \\
\text { forming organs }\end{array}$ & 5.9 & 3.7 & 4.5 & 3.0 & 4.8 \\
\hline Mental disorders & 5.5 & 3.5 & 4.5 & 3.0 & 2.9 \\
\hline $\begin{array}{l}\text { Nervous system and } \\
\text { sense organs }\end{array}$ & 2.5 & 1.6 & 1.9 & 1.3 & 1.6 \\
\hline Circulatory system & 31.2 & 53.6 & 34.1 & 55.2 & 56.6 \\
\hline Respiratory system & 5.6 & 3.5 & 13.0 & 8.8 & 6.2 \\
\hline Digestive system & 5.0 & 3.2 & 4.9 & 3.3 & 2.7 \\
\hline Genitourinary system & 4.1 & 2.6 & 3.8 & 2.6 & 3.3 \\
\hline $\begin{array}{l}\text { Complications of } \\
\text { pregnancy, childbirth, } \\
\text { puerperium }\end{array}$ & 0.1 & 0.1 & 0.2 & 0.1 & 0.0 \\
\hline $\begin{array}{l}\text { Skin and subcutaneous } \\
\text { tissue }\end{array}$ & 4.0 & 2.5 & 1.1 & 0.7 & 1.0 \\
\hline $\begin{array}{l}\text { Musculoskeletal } \\
\text { system and connective } \\
\text { tissue }\end{array}$ & 5.0 & 3.2 & 3.2 & 2.2 & 2.6 \\
\hline Congenital anomalies & 0.4 & 0.3 & 0.4 & 0.3 & 0.1 \\
\hline $\begin{array}{l}\text { Conditions in the } \\
\text { perinatal period }\end{array}$ & 0.0 & 0.0 & 0.0 & 0.0 & 0.0 \\
\hline $\begin{array}{l}\text { Symptoms, signs, and } \\
\text { ill-defined conditions }\end{array}$ & 5.8 & 3.7 & 7.4 & 5.0 & 3.8 \\
\hline Injury and poisoning & 2.8 & 4.6 & 2.6 & 1.8 & 1.6 \\
\hline
\end{tabular}

$D V T=$ deep vein thrombosis; $P E=$ pulmonary embolism. 